
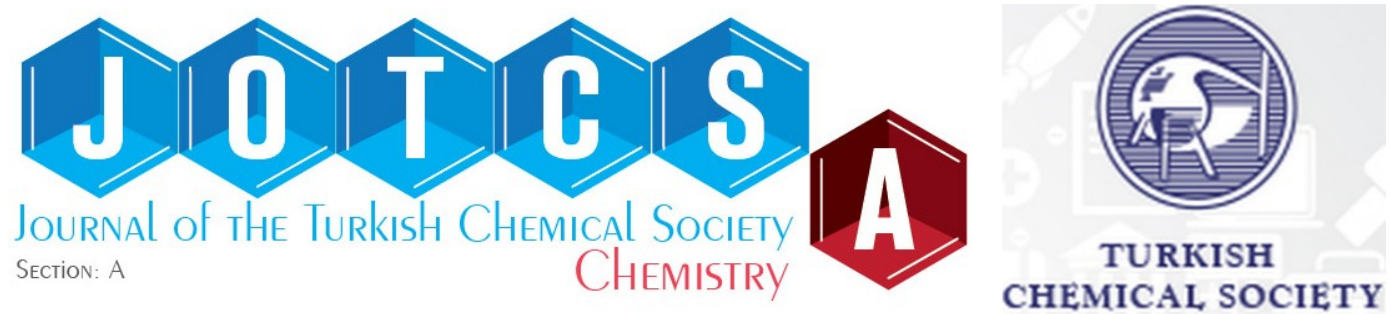

\title{
Poly(glutamic acid) Modified Pencil Graphite Electrode for the Voltammetric Determination of Bisphenol A
}

\author{
Ozge Gorduk*
}

Yildiz Technical University, Faculty of Arts and Science, Department of Chemistry, 34210, Istanbul, Turkey.

\begin{abstract}
Bisphenol A (BPA), which is an endocrine-disrupting substance, is often utilized as beverage and food packing material, and it may accumulate in nutrition and water sources, which is why it is important to monitor. In this study, for the determination of bisphenol A, electro-polymerization of glutamic acid (GA) was performed on a pencil graphite electrode (PGE). The performance of the sensor (PGA/PGE) for determining bisphenol A was examined utilizing the cyclic voltammetric (CV) and differential pulse voltammetric (DPV) methods. Electrochemical characterization process of the PGA/PGE was carried out by the electrochemical impedance spectroscopy (EIS) and CV methods. The morphological property of the PGA/PGE was investigated by scanning electron microscopy (SEM). The presence of functional groups in the PGA/PGE composition was characterized by Fourier transform infrared spectroscopy (FTIR). The electrochemical behavior of BPA was observed with the bare PGE and the PGA/PGE. Based on the findings, the response of BPA was considerably raised with PGA/PGE. With the optimized parameters and based on the findings from DPV, the BPA oxidation current was linear in a concentration interval of 1.0 to $100 \mu M(R=0.9992)$, and the detection limit was found to be $0.37 \mu \mathrm{M}$. Detection of BPA in the plastic bottled drinking water sample using PGA/PGE was performed successfully, and the recoveries were in the range of 89.3 to $104.7 \%$. This strategy can provide several prospects in electrochemically determining BPA in practical applications.
\end{abstract}

Keywords: Glutamic acid, Electro-polymerization, Bisphenol A, Pencil Graphite Electrode, Voltammetric determination.

Submitted: April 28, 2020. Accepted: December 15, 2020.

Cite this: Gorduk O. Poly(glutamic acid) Modified Pencil Graphite Electrode for the Voltammetric Determination of Bisphenol A. JOTCSA. 2021;8(1):173-86.

DOI: https://doi.org/10.18596/jotcsa.728165.

*Corresponding author. E-mail: ozgekyn34@gmail.com, okoyun@yildiz.edu.tr, Tel: +90(212)3834150.

\section{INTRODUCTION}

Bisphenol A (BPA), with its International Union of Pure and Applied Chemistry (IUPAC) name called 4,4'-(propane-2,2-diyl)diphenol, is among the most frequently utilized substances around the world to produce epoxy and polycarbonate resins employed for packaging, food storage, bottles and beverage cans (1-3). The common usage of BPA has led it to infiltrate into food and water from packaging materials, causing human and aquatic organisms to be exposed to it (4). The existence of phenolic compounds in the composition of BPA is like the compounds in endocrine hormones, especially estradiol and diethylstilbestrol and causes binding to estrogen receptors $(5,6)$. Therefore, BPA is recognized as an endocrine-disrupting compound
(EDC) $(1,5)$. It is also thought to be related to the emergence of various health effects like diabetes, birth defects, infertility, cardiovascular disease, and developmental neurotoxicity. Even more crucially, BPA can lead to an increase in the prevalence of some types of cancer $(6,7)$.

The main origin of BPA contact in humans is water, beverages, and food because of its transfer from plastic vessels to nutrition products (4). When the negative effects of BPA reported on human health are evaluated, it has become very important to determine the concentration of BPA, which can contaminate foods and beverages (8). With the increasing momentum in recent years, studies on BPA determination have begun to enter the literature. When the literature is examined, it is seen 
that there are many analytical methods used for BPA determination. These methods include highperformance liquid chromatography (9), electrochemical methods (1, 10), gas chromatography (11), enzyme-linked immunosorbent (12), molecular suppression (13) and fluorimetry (14). Among these methods, electrochemical methods have several benefits such as speed, minimal cost, simple usage, good sensitivity, and satisfactory selectivity. Therefore, electrochemical methods are very attractive for BPA determination (15-17).

In the last few decades, using the electropolymerization method is of great significance in the construction of electrochemical sensors and biosensors due to its practical benefits like modification of the electrode, selectivity, good repeatability, electrochemical recycling, stability and low cost $(18,19)$. To reinforce this, there is much literature on the use of these modified electrodes for qualitatively and quantitatively determining BPA. A PGE is novel kind of carbon electrode and has been widely used recently (20-22). PGE has been utilized to identify a broad diversity of analytes using different voltammetric methods (23). PGE has many benefits over other carbon-based electrodes like low cost, surface polishing and no need for timeconsuming processes due to characteristics as disposability (18). The surface may be modified effortlessly, and it has high electrochemical reactivity and surface area (19).

Glutamic acid (GA) is among twenty widespread amino acids that may be effortlessly electropolymerized on the electrode surface to create poly(glutamic acid) (PGA) (24, 25). PGA includes glutamate repeat units and free protonated carboxylic groups $(\mathrm{pKa}=4.45)$ by linking $\alpha$-amino and $\delta$-carboxylic acid functional substances, which show enhanced properties in electrochemical applications (26). Studies on the electropolymerization of GA on different electrode platforms are included in the literature (26-32).

Herein, a polymer-based electrode, which can be fabricated in one step, was prepared by the electropolymerization process using the cyclic voltammetric method. The PGA/PGE displayed effective catalytic properties in the electrochemical determination of bisphenol $A$. The sensor (PGA/PGE) was effectively utilized to determine BPA alongside potential interferences. The sensitivity, linear range, LOD, LOQ, and measurements in the plastic bottled drinking water sample were additionally shown. The presented electrochemical sensor offers chances for creating a simple, cost-efficient and effortless method in water quality observation.

\section{MATERIAL AND METHODS}

\section{Chemicals and Apparatus}

All the chemical materials (bisphenol A, potassium hexacyanoferrate(II) trihydrate, L-glutamic acid, potassium hydroxide, lithium perchlorate, potassium
hexacyanoferrate(III), and phosphoric acid) used in the experimental processes were purchased from the Sigma-Aldrich Company. Besides, potassium hydrogen phosphate and potassium dihydrogen phosphate chemicals used in the preparation of phosphate buffer solution (PBS) were obtained from Merck Company. All of the chemicals used during this study are of analytical grade. The plastic bottled drinking water sample was bought from a local shop. Distilled water used during experimental studies was obtained from a Millipore Milli-Q Direct 16

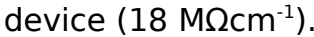

Voltammetric measurements were performed using the Autolab PGSTAT128N instrument. Gamry Reference 3000 Potentiostat/Galvanostat system was used for electrochemical impedance spectroscopy (EIS) measurements. During the experiments, the conventional 3-electrode system was used. In this context, pencil graphite (Tombow $0.5 \mathrm{HB}), \mathrm{Ag} / \mathrm{AgCl}$, and Pt wire are used as working electrode, reference electrode, and counter electrode, respectively. The $\mathrm{pH}$ measurements were carried out with a Mettler Toledo $\mathrm{pH}$ meter at room temperature. FTIR data was recorded using the Perkin Elmer spectrophotometer with ATR sampling accessory. Ultraviolet-visible measurements were performed with the Agilent 8453 UV/Vis spectrophotometer. For the investigation of the surface morphology, SEM Zeiss Evo LS 10 device was made use of

\section{Fabrication of poly(glutamic acid) modified pencil graphite electrode}

The fabrication of the PGA/PGE to be utilized in the electrochemical detection of the bisphenol A was performed in one step. Firstly, electrodes with 10 cycles of film thickness in PBS pH 7.0 containing different concentrations of glutamic acid monomer $(0.001,0.01$ and $0.1 \mathrm{M})$ were prepared to optimize the monomer concentration. The performances of the prepared electrodes were compared using both CV and DPV methods in the solution containing 100 $\mu \mathrm{M}$ BPA and it was observed that the highest oxidation response belongs to the concentration of $0.01 \mathrm{M}$ glutamic acid. Therefore, the optimized monomer concentration was chosen as $0.01 \mathrm{M}$. Then, polymerization of $0.01 \mathrm{M}$ GA in PBS at different $\mathrm{pHs}(4.0,5.0,6.0,7.0$, and 8.0) was investigated to examine the $\mathrm{pH}$ effect on the polymerization solution. The optimum $\mathrm{pH}$ value for the controlled growth of the film thickness was found to be 7.0. The modification was carried out in $0.01 \mathrm{M} \mathrm{L-glutamic}$ acid solution which was arranged in $0.1 \mathrm{M}$ PBS $\mathrm{pH} 7.0$ at scan rate of $50 \mathrm{mV} / \mathrm{s}$. CV method was employed to carry out the electropolymerization procedure. According to the aim, varying polymerization potentials equaling $2.3,2.2$, $2.1,2.0$, and $1.9 \mathrm{~V}$ to $-0.5 \mathrm{~V}$ were implemented. The best peak current for BPA was achieved with the prepared electrode under conditions where the electropolymerization process was provided between -0.5 and $2.0 \mathrm{~V}$ potential. The measurements were conducted at under the 
optimum conditions 10 cycles and a scan rate of 50 $\mathrm{mV} / \mathrm{s}$, in the potential range $-0.5 \mathrm{~V}$ to $2.0 \mathrm{~V}$. The electrode obtained after this procedure was coded as PGA/PGE and washed by double-dipping in distilled water and dried at room temperature in a desiccator

\section{Electrochemical measurement}

To investigate the electrochemical determination of the BPA, various voltammetric methods were performed. Cyclic voltammetric (CV) and differential pulse voltammetric (DPV) methods were used for the electrochemical characterization of PGA/PGE, determination and detection of BPA. The voltammetric measurements were actualized in 0.1 $\mathrm{M}$ pH 4.0 PBS containing $100 \mu \mathrm{M}$ BPA and were performed at room temperature. During the measurements, PGA/PGE was immersed in the analyte solution at a length of $1.0 \mathrm{~cm}$ in order to keep the surface area constant. CV and DPV signals were recorded in a potential range of 0.0 to $1.0 \mathrm{~V}$. New electrodes were used for each measurement.

\section{Preparation of real sample}

In this study, real sample studies were made with plastic bottled drinking water samples bought from a local shop in Turkey and utilized with no pretreatment. For examination, $2.5 \mathrm{~mL}$ of the plastic bottled drinking water sample was diluted to 10.0 $\mathrm{mL}$ with PBS $\mathrm{pH}$ 4.0. Before the analysis, the water sample was freshly prepared. It was mixed in the ultrasonic bath for 10 minutes, and then analysis was carried out.

\section{RESULTS AND DISCUSSION}

\section{Electro-polymerization of glutamic acid}

The PGA/PGE was produced by immersing the bare PGE in a PBS pH 7.0 containing $10.0 \mathrm{mM} \mathrm{GA}$ monomer and recording cyclic voltammograms taken at $50 \mathrm{mV} / \mathrm{s}$ scan rate and potential range of 0.5 to $2.0 \mathrm{~V}$. In Figure 1 , it is seen that the oxidation signal at $1.75 \mathrm{~V}$ in the first cycle decreases and disappears in after second cycle. This is thought to be related to the polymerization of the monomeric molecules. Here, it can be observed that the oxidation peak signals are increased with step by step each cycle the formation and development of an electroactive layer on the PGE surface. After the ninth cycle, the rise of this peak current is almost constant and more stable, indicating that the growth of polymerization has reached the saturation level. The reaction mechanism of the GA for the electropolymerization process is shown in Scheme 1 (28).

According to the experimental findings obtained, the thickness of the film had a significant effect on the electrocatalytic property of PGE (33). The degree of thickness was also adjusted. The coating was managed by changing the number of multiple cycles $(3,5,7,10$, and 15 cycles) on PGE and the relevant electrocatalytic activity for the oxidation of $100 \mu \mathrm{M}$ BPA in PBS pH 4.0 was examined. As seen in Figure 2 , the oxidation peak current of BPA has reached its peak in 10 cycles. Therefore, 10 cycles were selected for the electro-polymerization of GA. Initially, the electrocatalytic response of BPA also increased with an increase in the number of polymerization cycles. However, when the number of polymerization cycles was more than 10, the peak currents of the oxidation signal of BPA did not show a significant increase. This is because the film thickness hinders electron transfer after reaching certain saturation (34). Thus, electrodes with 10 cycles of film thickness were used for all electrochemical analyses.

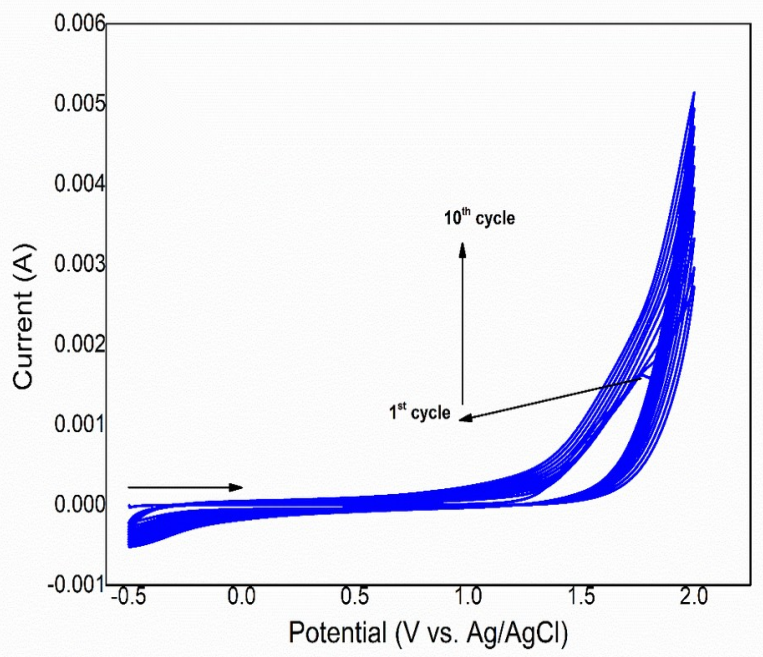

Figure 1: Cyclic voltammograms of electro-polymerization of GA on PGE in PBS pH 7.0 containing 10.0 mM L-glutamic acid at between -0.5-2.0 V potential range, 10 cycles, at scan rate of $50 \mathrm{mV} / \mathrm{s}$. 


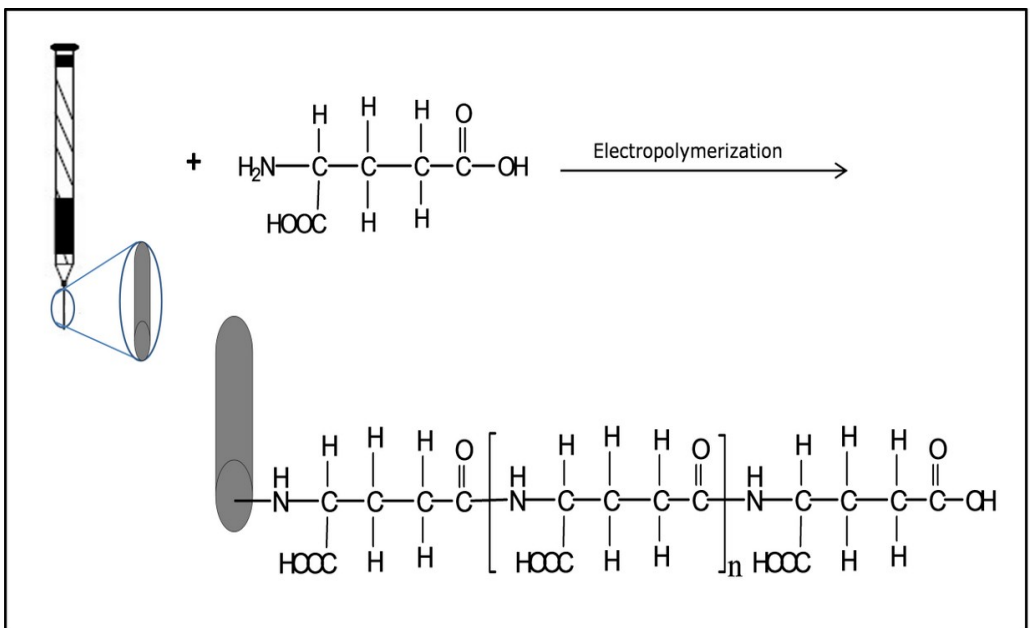

Scheme 1: The reaction mechanism of the GA for the electropolymerization on the surface PGE.

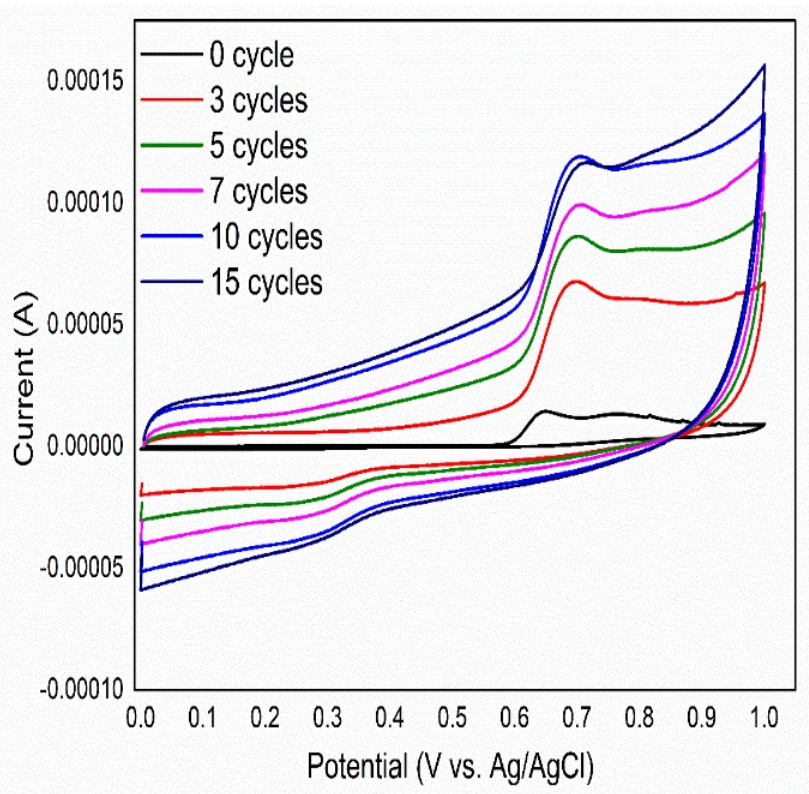

Figure 2: Cyclic voltammograms of PGA/PGEs with different number of cycles in PBS pH 4.0 containing $100 \mu \mathrm{M}$ BPA at scan rate of $50 \mathrm{mV} / \mathrm{s}$ and the potentia range of $0.0 \mathrm{~V}$ to $1.0 \mathrm{~V}$.

\section{Characterization studies}

The redox types of $\mathrm{Fe}(\mathrm{CN})_{6}^{4-13-}$ were selected for the electrochemical identification experiment. The cyclic voltammograms of $\mathrm{Fe}(\mathrm{CN})_{6}{ }^{4-13-}(2.5 \mathrm{mM})$ were acquired by bare PGE and PGA/PGE in Figure 3 (21). We determined well-identified oxidation and reduction peaks with the bare PGE at 0.27 and 0.19 $\mathrm{V}$. Oxidation and its matching cathodic peak were seen with PGA/PGE at 0.28 and $0.18 \mathrm{~V}$, respectively. As shown in Figure 3, the oxidation potential of $\mathrm{Fe}(\mathrm{CN})_{6}{ }^{4-}$ redox species shifted to the anodic direction and the reduction potential of $\mathrm{Fe}(\mathrm{CN})_{6}{ }^{3-}$ redox species shifted to the cathodic direction in the presence of PGA as modifiers according to bare PGE. Besides, in the case of PGA/PGE, peak currents were significantly raised, showing that the PGA/PGE has a high electroactive surface area, good

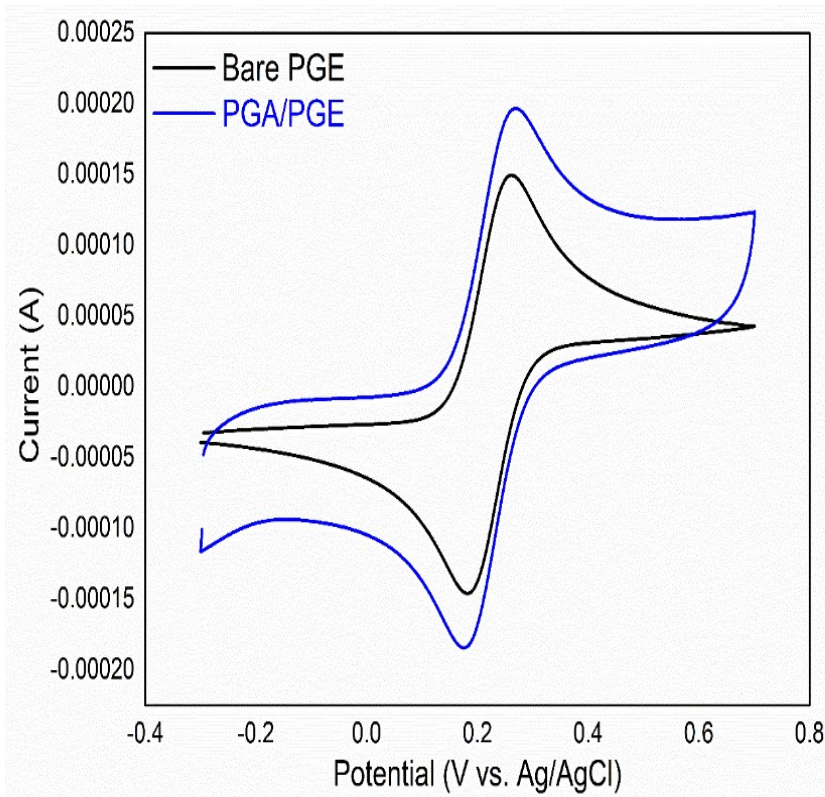

Figure 3: Cyclic voltammograms of bare PGE and PGA/PGE in $2.5 \mathrm{mM} \mathrm{Fe}(\mathrm{CN})_{6}^{3-14-}+0.1 \mathrm{M} \mathrm{KCl}$, at

potential range of $-0.3-0.7 \mathrm{~V}$, at scan rate of $50 \mathrm{mV} / \mathrm{s}$.

electrochemical properties, and ability to the electrostatic pull of the $\mathrm{Fe}(\mathrm{CN})_{6}^{4-/ 3-}$ redox pair (23).

EIS may provide useful information about the impedance alterations of the electrode surface to describe the sensor's construction procedure. The capacity of electron transfer of bare PGE and PGA/PGE was additionally investigated by utilizing EIS, as demonstrated in Figure 4. The Nyquist plots of the bare and modified electrodes were constructed in $1.0 \mathrm{mM} \mathrm{K}_{3}[\mathrm{Fe}(\mathrm{CN})]_{6}+0.1 \mathrm{M} \mathrm{KCl}$ solution. The spectra were matched in known corresponding circuit model as given in Figure 4 (inset), commonly given by the literature $(35,36)$. The greater electrocatalytic activity of PGA/PGE was shown by the drop in charge transfer resistance (Rct). The semicircle diameter at greater 
frequencies corresponds to the Rct, and the linear part at lower frequencies corresponds to the diffusion procedure (19). The values of charge transfer resistance were determined by fitting the data utilizing an appropriate corresponding circuit to be 105 and $723 \Omega$ for the bare PGE and PGA/PGE, respectively. The findings here show that $P G A / P G E$ for $\mathrm{Fe}(\mathrm{CN}) 64-/ 3$ - had a higher electron transfer rate and capacity than the bare PGE (18).

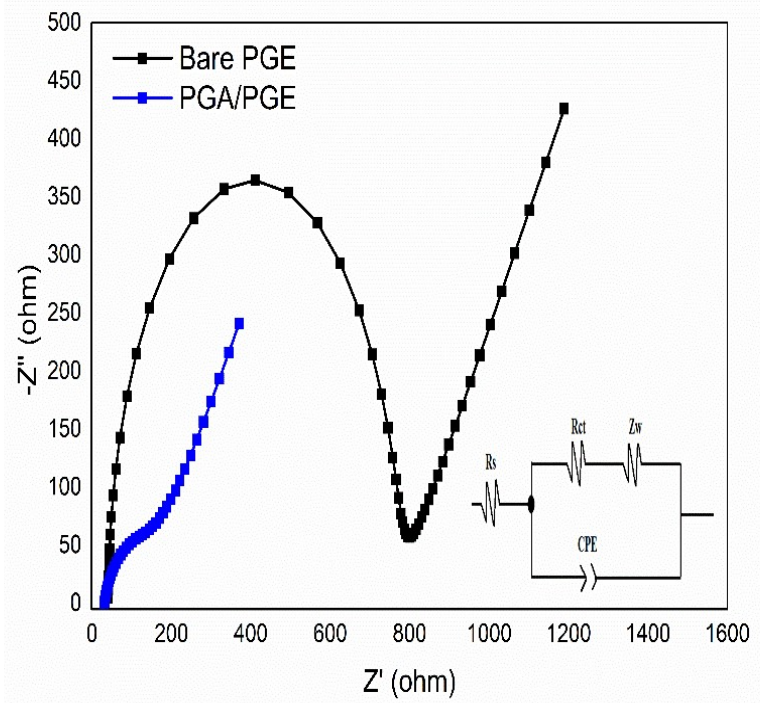

Figure 4: Nyquist plots of bare PGE and PGA/PGE in $5.0 \mathrm{mM} \mathrm{Fe}(\mathrm{CN})_{6}^{3-14-}+0.1 \mathrm{M} \mathrm{KCl}$ solution. Inset: Simple circuit model utilized process (Rs, Rct, Zw, and CPE represent solution resistance, charge transfer resistance, Warburg impedance, and constant phase element, respectively).

SEM examinations were performed for determining the morphological properties of the PGA/PGE. Goldpalladium sputter coating was performed under 120 seconds and $100 \AA$ conditions before all images were taken. The SEM results from our previous studies show that the graphite layers on the bare PGE surface have a flat structure $(18,23)$. When the literature is examined, the SEM images obtained by electro-polymerization of amino acids on the surface of carbon-based electrodes are often similar, and the signs of modification are relatively mild $(18,19)$. In Figure 5, when examining the images of the modified electrode at different rates of magnification, it is possible to say that the structures that are rough polymeric on the electrode surface come to the fore. The porous nanodimensional polymeric structure formed on the electrode surface, providing high specific surface area and channels of ion diffusion and pathways of electron transport $(28,37)$. Here, the PGA films increased the surface area of the flat bare PGE which increases the sensitivity of the electrode for bisphenol A. In this context, it is possible to interpret the poly(glutamic acid) structure on the electrode surface from SEM micrographs. 


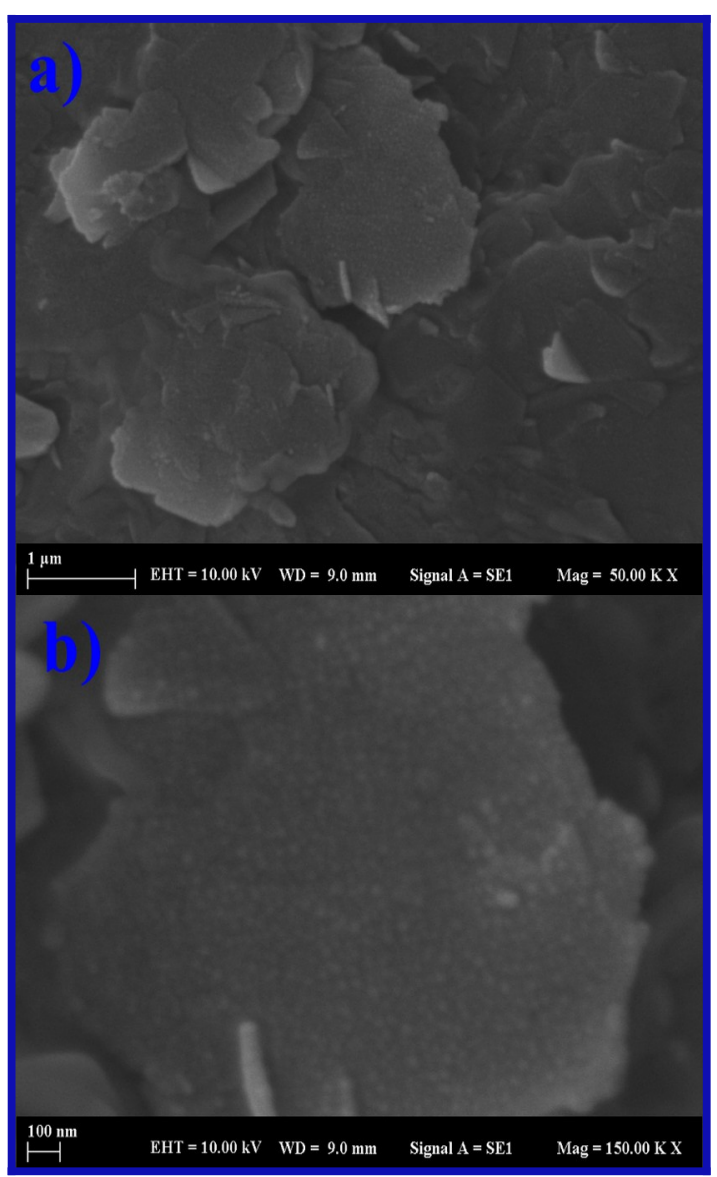

Figure 5: SEM micrographs of a) PGA/PGE (with 50000 magnifications) and b) PGA/PGE (with 150000 magnifications).

FTIR was used to characterize the presence of functional groups in the PGA/PGE composition. Thus, the formation of functional groups belonging to polyglutamic acid formed by electro-polymerization of GA on the electrode surface was examined (Figure 6). As seen in Figure 6, the bands that appear different from the bare PGE spectrum, the broad peak at $3000-3500 \mathrm{~cm}^{-1}$ was the vibration stretching band of $\mathrm{N}-\mathrm{H}$ and $\mathrm{COOH} ; 1652 \mathrm{~cm}^{-1}$ was the vibration stretching band carbonyl group $(C=O)$; $1074 \mathrm{~cm}^{-1}$ was the most obvious peak representing the presence of aliphatic hydrocarbons, $-\mathrm{CH}_{2}$ or $\mathrm{CH}_{3}$; proving that the electro-polymerization process was successful (38).

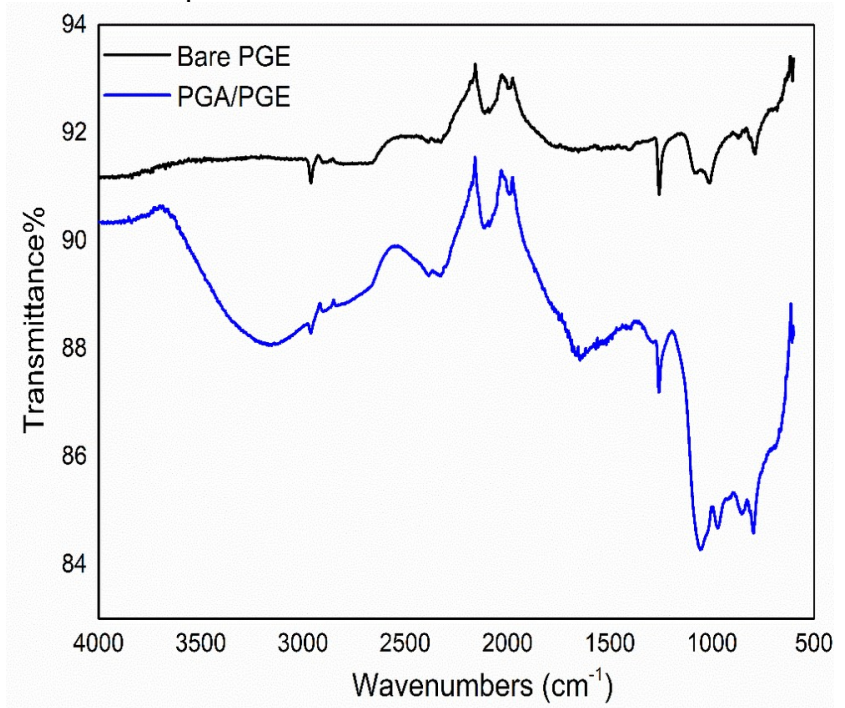

Figure 6: FTIR spectra of bare PGE and PGA/PGE. 
Electrochemical oxidation of bisphenol $A$ at PGA/PGE

As is known, BPA is an electroactive compound. Therefore, cyclic voltammograms were recorded on the surfaces of different electrodes in order to investigate the redox behavior and also evaluate the ability of the modifier agent to improve electrode performance for BPA determination. Both bare PGE and PGA/PGE have demonstrated oxidation responses that confirm the electroactive nature of BPA. Figure 7 displays the cyclic voltammograms obtained for $100 \mu \mathrm{M}$ BPA at the bare PGE and PGA/PGE in PBS $(0.1 \mathrm{M}) \mathrm{pH} 4.0$ with a scanning rate of $50 \mathrm{mV} / \mathrm{s}$. The BPA shows the oxidation current with a good response. The oxidation potential was seen at $0.65 \mathrm{~V}$ at $\mathrm{a}$ bare pencil graphite electrode.
However, in the same condition, PGA/PGE displayed significant improvement in the current signals, and the potential of oxidation was found at $0.70 \mathrm{~V}$. It was observed that the oxidation signal of the BPA shifts in the anodic direction when the working electrode is PGA/PGE. Here, the noticeable enhancement of peak current demonstrates the electrocatalytic action of PGA/PGE towards the detection of bisphenol A (39). As a result, PGA/PGE showed the maximum intensity of the electrochemical signal, demonstrating that PGA exhibited higher electroconductivity, which could be resulted from the synergistic impact and good properties of modifiers, namely, high surface area, great electrical conductivity and much more sites for electroactive species.

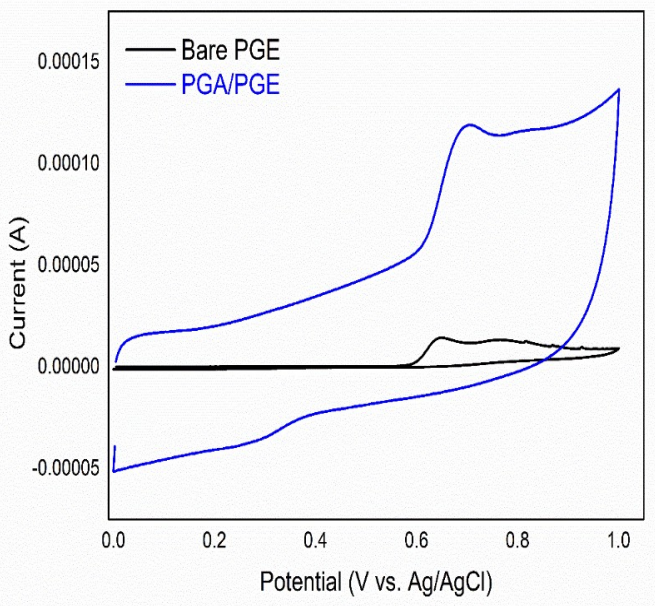

Figure 7: Cyclic voltammograms of bare PGE and PGA/PGE in PBS pH 4.0 containing $100 \mu \mathrm{M}$ BPA, at potential range of $0.0-1.0 \mathrm{~V}$, and scan rate of $50 \mathrm{mV} / \mathrm{s}$.

Influence of $\mathrm{pH}$ on the detection of bisphenol $A$ at PGA/PGE

The $\mathrm{pH}$ of the PBS has a considerable influence on the electrochemical response of BPA at the PGA/PGE by influencing peak potential and peak current. The influence of the PBS $\mathrm{pH}$ value on determining BPA at PGA/PGE was meticulously assessed in a wider $\mathrm{pH}$ interval of 4.0-8.0. Figure 8 shows cyclic voltammograms recorded for $100 \mu \mathrm{M}$ BPA at PGA/PGE. The oxidation peak potential moves to a more negative potential by higher $\mathrm{pH}$. The peak potential versus $\mathrm{pH}$ plot showed that the peak potential is linearly dependent on the $\mathrm{pH}$ value in the interval of 4.0-8.0 with a slope of $0.0656 \mathrm{~V} / \mathrm{pH}$ $\left(R^{2}=0.9957\right)$ as demonstrated in Figure 9. This finding suggests there exists an equal quantity of protons and electrons taking part in the redox process. According to Bard and Faulkner (40), the transferred electron number in the BPA oxidation reaction was found as approximately 2 (41). Therefore, the reaction in Scheme 2, for the electrooxidation of BPA on the surface of PGA/PGE can be suggested, where 2 electrons and 2 protons participate in the electrode reaction. This was in agreement with that stated in the literature (42). 


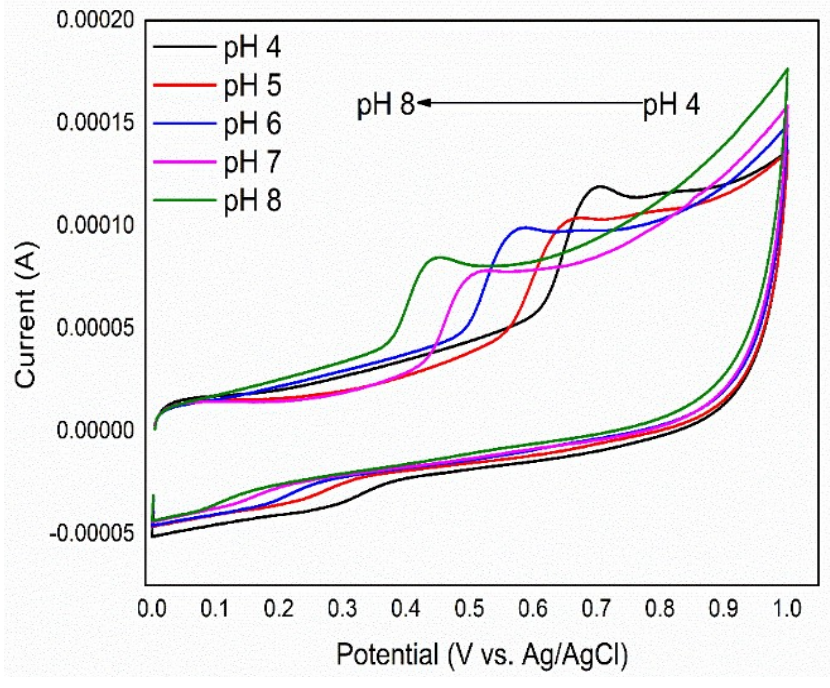

Figure 8: Cyclic voltammograms of PGA/PGE prepared at 10 polymerization cycles in the $4.0,5.0$, $6.0,7.0$, and $8.0 \mathrm{pH}$ values PBS containing $100 \mu \mathrm{M}$ BPA.

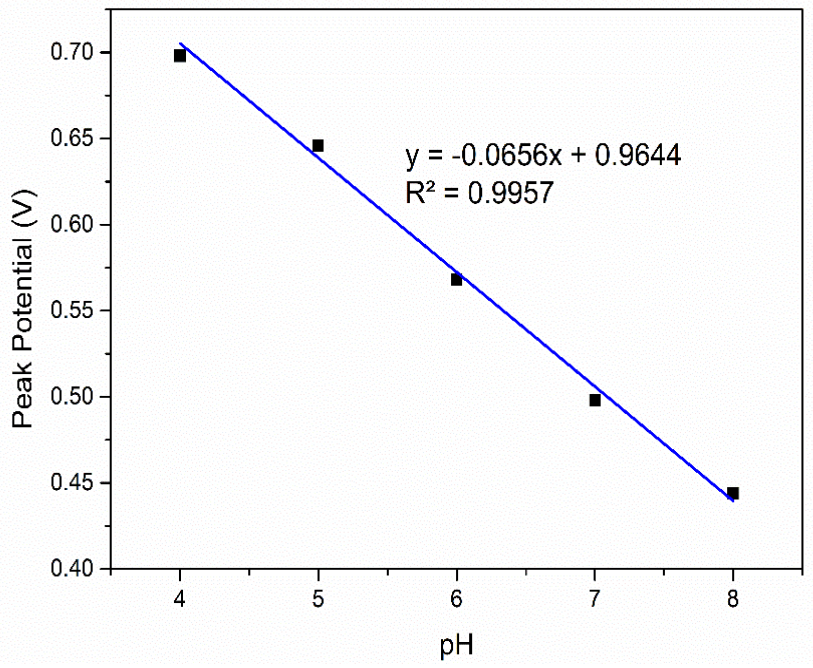

Figure 9: Graph showing the variation of the peak current responses of PBS containing $100 \mu \mathrm{M}$ BPA with $\mathrm{pH}$ value.<smiles>CC(C)(c1ccc(O)cc1)c1ccc(O)cc1</smiles>

Scheme 2: The possible oxidation mechanism of BPA at PGA/PGE.

Influence of potential scan rate on response oxidation peak current of BPA

The influence of changing the employed scan rate for $100 \mu \mathrm{M}$ BPA in PBS $\mathrm{pH} 4.0$ was examined by the $\mathrm{CV}$ technique at the PGA/PGE as demonstrated in Figure 10. The experiment findings acquired from the PGA/PGE displayed a rise in the peak currents with higher applied scanning rate, and they were proportional to each other based on the RandlesSevcik equation (43). The finding suggested that there was a shift of the oxidation peak potential towards the less negative side. To validate the electrode process, the plot of the peak current versus square roots of scanning rate was drawn, and the resulting plot was a straight line with satisfactory linearity in the interval from 25 to 500 $\mathrm{mV} / \mathrm{s}$ as presented in Figure 11 with the correlation coefficient $\left(R^{2}\right)$ of 0.9978 . These results indicate that the electrode process is diffusion-controlled $(28,43)$. 

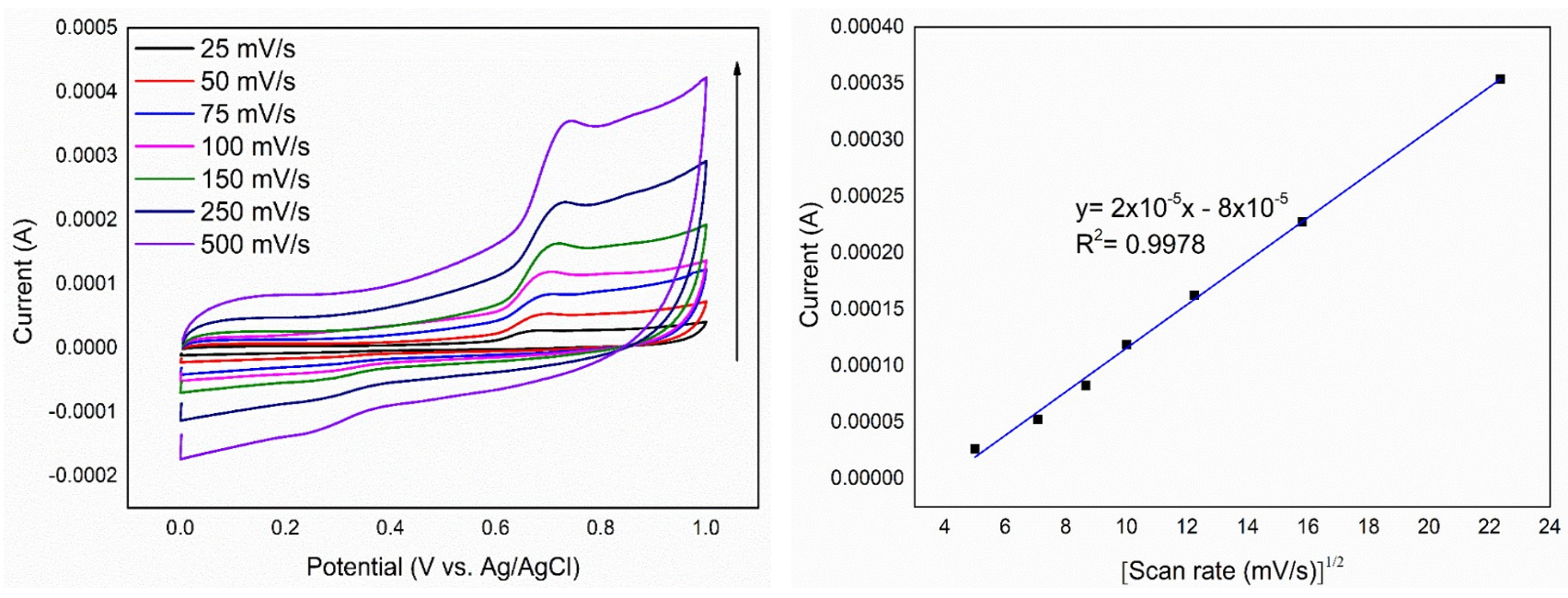

Figure 10: Cyclic voltammograms of the PGA/PGE at Figure 11: Graph showing the linear relationship scan rates of $25 \mathrm{mV} / \mathrm{s}, 50 \mathrm{mV} / \mathrm{s}, 75 \mathrm{mV} / \mathrm{s}, 100 \mathrm{mV} / \mathrm{s}$, $150 \mathrm{mV} / \mathrm{s}, 250 \mathrm{mV} / \mathrm{s}$, and $500 \mathrm{mV} / \mathrm{s}$ in PBS pH 4.0 containing $100 \mu \mathrm{M}$ BPA.

\section{Analytical performance of the sensor toward BPA determination}

A set of BPA solutions was created at a falling concentration starting from $1.0 \mu \mathrm{M}$ to compute the identification and determination limit of the created PGA/PGE. The voltammograms acquired by differential pulse voltammetric method in the potential interval of $0.5 \mathrm{~V}$ to $1.0 \mathrm{~V}$ using the modified electrode in every solution are presented (Figure 12). By utilizing the voltammograms in Figure 12, a calibration plot that provides the current-concentration relationship shown in Figure 13 was obtained. As a consequence of the computations conducted from the calibration plot, the LOD value was found as $0.37 \mu \mathrm{M}(\mathrm{S} / \mathrm{N}=3)$, and the LOQ value was found as $1.24 \mu \mathrm{M}(\mathrm{S} / \mathrm{N}=10)$. The linear regression equation of PGA/PGE is $I(A)=$ $0.142 C_{B P A}(M)+2 \times 10^{-7}, R^{2}=0.9992$. The comparison of the analytical performances of some polymerbased electrodes in the literature is presented in Table 1.

\section{Interference studies}

Various compounds and ions like methanol, phenol, $\mathrm{SO}_{4}{ }^{2-}, \mathrm{Na}^{+}, \mathrm{Cl}^{-}, \mathrm{Cu}^{2+}, \mathrm{Fe}^{3+}, \mathrm{Pb}^{2+}, \mathrm{K}^{+}$and $\mathrm{Cd}^{2+}$ may be utilized in the synthesis and structure determination of packing materials (10). For identifying the influences of these materials on the electrochemical between the square roots of the scan rate with oxidation peak current.

determination of BPA, we investigated the variation in current by introducing these materials to the BPA solutions in the DPV analyses.

The interferent species were individually added to $5.0 \mu \mathrm{M}$ of BPA solutions. When potassium chloride and sodium carbonate (500 $\mathrm{MM}$ each) were added, variations in the oxidation current of BPA in the DPV analysis were not seen. The concentration of every interference was more than at least 100 times higher than the BPA concentration in the detection of the interference influence in the DPV examination. Methanol $(5000 \mu \mathrm{M})$ was also introduced to $5.0 \mu \mathrm{M}$ BPA solutions, and a reduction in the anodic peak current was found, smaller than that of $5 \%$. The effects of $1000 \mu \mathrm{M}$ of $\mathrm{Fe}^{2+}, \mathrm{Cd}^{2+}, \mathrm{K}^{+}$, and $\mathrm{Pb}^{2+}$, which have been utilized in several industrial procedures and are found in some water samples, were additionally examined for the analytical response of BPA utilizing the modified electrode in the DPV examination, shown in Table 2. This demonstrated that PGA/PGE has selectivity for BPA and may be utilized to electrochemically determine BPA in several real samples. 

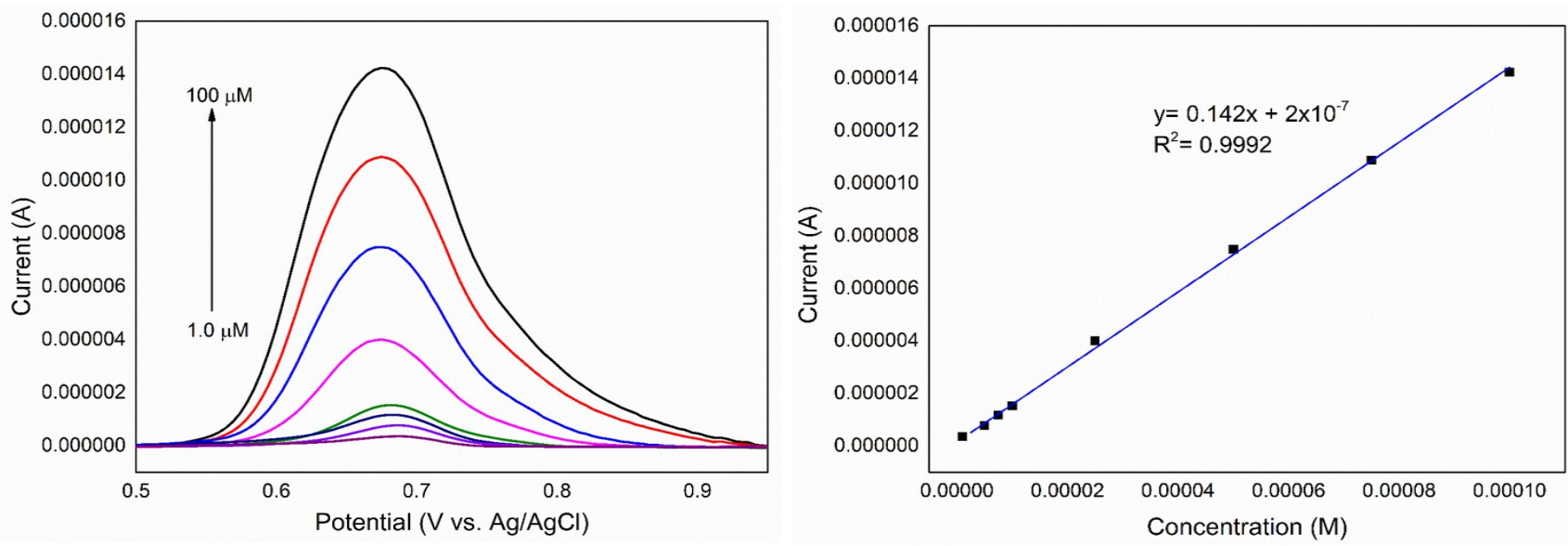

Figure 12: Differential pulse voltammograms of PGA/ Figure 13: Calibration graph of current-concentration PGE in different concentrations of BPA solutions. $(100,75.0,50.0,25.0,10.0,7.5,5.0,1.0 \mu \mathrm{M}$ concentrations of BPA in PBS pH 4.0).

Table 1: Comparison of some polymer-based sensor platforms in the literature for BPA determination.

\begin{tabular}{|c|c|c|c|c|}
\hline Sensor & $\begin{array}{l}\text { Electrochemical } \\
\text { method }\end{array}$ & $\begin{array}{l}\text { Linear } \\
\text { range } \\
\text { ( } \mu \mathrm{M})\end{array}$ & $\begin{array}{l}\text { Limit of } \\
\text { detection } \\
(\mu \mathrm{M})\end{array}$ & Reference \\
\hline $\begin{array}{l}\text { Tyrosinase/poly(thionine)/ } \\
\text { Glassy Carbon Electrode }\end{array}$ & Amperometry & 400 & 23.0 & $(44)$ \\
\hline $\begin{array}{l}\text { Multi-walled Carbon } \\
\text { Nanotubes/Poly } \\
\text { (Crystal Violet)/Glassy } \\
\text { Carbon Electrode }\end{array}$ & $\begin{array}{l}\text { Linear Sweep } \\
\text { Voltammetry }\end{array}$ & $0.05-100$ & 0.01 & $(45)$ \\
\hline $\begin{array}{l}\text { Poly }(3,4 \\
\text { ethylenedioxythiophene) } \\
\text { Glassy Carbon Electrode }\end{array}$ & Cyclic Voltammetry & $90-140$ & 55 & (46) \\
\hline $\begin{array}{l}\text { Molecularly Imprinted } \\
\text { Polymer-Modified } \\
\text { Multiwalled } \quad \text { Carbon } \\
\text { Nanotube Paste Electrode }\end{array}$ & $\begin{array}{l}\text { Differential Pulse } \\
\text { Voltammetry }\end{array}$ & $0.08-100$ & 0.022 & $(47)$ \\
\hline $\begin{array}{l}\text { Poly(Chromotropic } \\
\text { Acid)/Glassy } \\
\text { Electrode }\end{array}$ & $\begin{array}{l}\text { Square wave } \\
\text { voltammetry }\end{array}$ & $0.1-20$ & 0.06 & $(48)$ \\
\hline 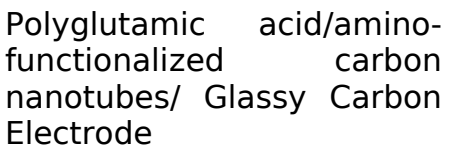 & $\begin{array}{l}\text { Differential Pulse } \\
\text { Voltammetry }\end{array}$ & $0.1-10$ & 0.02 & (49) \\
\hline $\begin{array}{l}\text { Poly(glutamic acid)/Pencil } \\
\text { Graphite Electrode }\end{array}$ & $\begin{array}{l}\text { Differential Pulse } \\
\text { Voltammetry }\end{array}$ & $1.0-100$ & 0.37 & This study \\
\hline
\end{tabular}

Table 2: Interference effects of some ion species on the oxidation peak response of $5.0 \mu \mathrm{M}$ of BPA.

\begin{tabular}{lcc}
\hline Species & $\begin{array}{c}\text { Current } \\
(\boldsymbol{\mu A})\end{array}$ & $\begin{array}{c}\text { Current } \\
\text { differences } \\
(\boldsymbol{\mu A})\end{array}$ \\
\hline $\mathrm{N} / \mathrm{A}$ & 1.08 & 0 \\
$\mathrm{Fe}^{2+}$ & 1.23 & +0.15 \\
$\mathrm{~K}^{+}$ & 1.19 & +0.11 \\
$\mathrm{Cd}^{2+}$ & 1.21 & +0.13 \\
$\mathrm{~Pb}^{2+}$ & 0.98 & -0.10 \\
\hline
\end{tabular}

\section{Reproducibility and stability of PGA/PGE}

Intraday and interday measurements were recorded to examine the reproducibility of the PGA/PGE. To examine intraday repeatability performance, DPVs of $5.0 \mu \mathrm{M}$ BPA were conducted using ten different
PGA/PGEs prepared just prior to the analysis. The percent relative standard deviation (RSD\%) was found to be $2.63 \%$. In order to investigate the repeatability performance interday, repeated measurements were made for ten days and the RSD 
$\%$ was found to be $3.21 \%$. These results demonstrated that the PGA/PGEs were replicable in their preparation. In addition, to examine the stability of the electrodes, DPV measurements were taken with electrodes held in a desiccator for 45 days. Hence, the difference between the starting and ending values was only $3.83 \%$. In conclusion, these findings demonstrated that the PGA/PGE was quite stable.

\section{Determination of BPA in real sample}

The spike recovery method was used to examine the usability of the proposed sensor platform in real samples. Electrochemical measurements were performed with DPV method. In order to examine the analytical applicability of the method measurements were also recorded with another analytical method, namely ultraviolet-visible spectrophotometry (50). The plastic bottled drinking water sample was obtained from the local shop and it was used directly without any pretreatment. The $2.5 \mathrm{~mL}$ plastic bottled drinking water was diluted with phosphate buffer solution $(10 \mathrm{~mL}, \mathrm{pH} 4.0)$. Then, 10 and $20 \mu \mathrm{M}$ standard BPA solutions were introduced to the diluted sample solution. Table 3 presents the obtained findings. Every measurement was replicated three times, and the RSD\% was computed. The recovery values were determined to be in the range of 89.3 to $104.7 \%$. The findings showed that the PGA/PGE could be applied to real sample analysis.

Table 3: Electrochemical detection of BPA in the plastic bottled drinking water sample with PGA/PGE.

\begin{tabular}{|c|c|c|c|c|c|}
\hline Sample & $\begin{array}{c}\text { Added } \\
\text { concentration } \\
\text { of bisphenol A } \\
(\mu \mathrm{M})\end{array}$ & $\begin{array}{c}\text { Found } \\
\text { concentration } \\
\text { of bisphenol A } \\
(\mu M)^{\mathrm{a}}\end{array}$ & $\begin{array}{c}\text { Found } \\
\text { concentration of } \\
\text { bisphenol } A \\
(\mu M)^{b}\end{array}$ & $\begin{array}{c}\text { Relative } \\
\text { standard } \\
\text { deviation } \\
(\%)^{\mathrm{b}}\end{array}$ & $\begin{array}{c}\text { Recovery } \\
(\%)^{b}\end{array}$ \\
\hline $\begin{array}{l}\text { Plastic } \\
\text { bottled }\end{array}$ & 10.0 & $10.9 \pm 0.032$ & $11.2 \pm 0.054$ & 2.3 & 89.3 \\
\hline $\begin{array}{l}\text { drinking } \\
\text { water }\end{array}$ & 20.0 & $21.3 \pm 0.034$ & $19.1 \pm 0.031$ & 2.6 & 104.7 \\
\hline
\end{tabular}

\section{CONCLUSION}

In this study, a modified electrode has been developed to determine BPA electrochemically. In the development phase of the electrode, the electropolymerization of glutamic acid was performed by $\mathrm{CV}$ method to obtain the PGA/PGE. The PGA/PGE was characterized by using the FTIR, SEM, EIS, and CV methods. Among the PGEs modified by the electropolymerization of glutamic acid, the most satisfactory findings were acquired with an electrode prepared by utilizing 10 electropolymerization cycles. Based on the measurement results taken at different $\mathrm{pH}$ values, the best peak current response was found at PBS $\mathrm{pH}$ 4.0. When the effect of scan rate on the oxidation mechanism of BPA is examined, it is concluded that the reaction is diffusion-controlled in the light of the findings obtained. BPA was electrochemically determined by utilizing the CV and DPV methods. The LOD and LOQ values for differential pulse voltammetric determination of BPA were $0.37 \mu \mathrm{M}$ and $1.24 \mu \mathrm{M}$, respectively. The reproducibility and stability of the newly developed sensor platform were examined. Finally, the applicability of PGA/PGE to plastic bottled drinking water sample was assessed. The recovery values were found to be between 89.3 and $104.7 \%$. The developed sensor platform stands out due to its low cost, easy and one-step preparation, and features such as good repeatability, sensitivity, and selectivity.

\section{ACKNOWLEDGMENT}

O. Gorduk especially thanks Prof. Dr. Yucel Sahin for his valuable contributions to this study.

\section{REFERENCES}

1. Alam AU, Deen MJ. Bisphenol A Electrochemical Sensor Using Graphene Oxide and $\beta$-Cyclodextrin-Functionalized Multi-Walled Carbon Nanotubes. Anal Chem. 2020; 92(7):5532-5539.

2. Ashraf G, Asif M, Aziz A, Wang Z, Qiu X, Huang Q, et al. Nanocomposites consisting of copper and copper oxide incorporated into $\mathrm{MoS}_{4}$ nanostructures for sensitive voltammetric determination of bisphenol A. Microchimica Acta. $2019 ; 186(6): 337$

3. Gugoasa LA, Stefan-van Staden RI, van Staden JF, Coros M, Pruneanu S, editors. Voltammetric determination of bisphenol A with a silver-reduced graphene oxide composite paste microsensor. 2019 International Semiconductor Conference (CAS); 2019: IEEE.

4. Bolat G, Yaman YT, Abaci S. Highly sensitive electrochemical assay for Bisphenol A detection based on poly (CTAB)/MWCNTs modified pencil graphite electrodes. Sens Actuators, B. 2018;255:140-8. 
5. Ezoji H, Rahimnejad M, Najafpour-Darzi G. Advanced sensing platform for electrochemical monitoring of the environmental toxin; bisphenol A. Ecotoxicology and Environmental Safety. 2020;190:110088.

6. Hu L, Fong C-C, Zhang X, Chan LL, Lam PK, Chu PK, et al. Au nanoparticles decorated $\mathrm{TiO}_{2}$ nanotube arrays as a recyclable sensor for photoenhanced electrochemical detection of bisphenol A. Environmental science \& technology. 2016;50(8):4430-8.

7. Bakirhan NK, Ozkan SA. The Recent Electrochemical Studies on Bisphenol A Detection in Beverages. Safety Issues in Beverage Production: Elsevier; 2020. p. 309-33.

8. Yaman YT, Abaci S. Sensitive adsorptive voltammetric method for determination of bisphenol A by gold nanoparticle/polyvinylpyrrolidone-modified pencil graphite electrode. Sensors. 2016;16(6):756.

9. Ji $Y$, Yin J, $X u Z Z$, Zhao $C$, Huang $H$, Zhang $H$, et al. Preparation of magnetic molecularly imprinted polymer for rapid determination of bisphenol $A$ in environmental water and milk samples. Analytical and bioanalytical chemistry. 2009;395(4):1125-33.

10. Koyun O, Gorduk S, Gencten M, Sahin Y. A novel copper (II) phthalocyanine-modified multiwalled carbon nanotube-based electrode for sensitive electrochemical detection of bisphenol $A$. New J Chem. 2019;43(1):85-92.

11. Malone E, Elliott C, Kennedy D, Regan L. Rapid confirmatory method for the determination of sixteen synthetic growth promoters and bisphenol $A$ in bovine milk using dispersive solid-phase extraction and liquid chromatography-tandem mass spectrometry. J Chromatogr B. 2010;878(1516):1077-84.

12. De Meulenaer B, Baert $K$, Lanckriet $H$, Van Hoed V, Huyghebaert A. Development of an enzymelinked immunosorbent assay for bisphenol A using chicken immunoglobulins. J Agric Food Chem. 2002;50(19):5273-82.

13. Zhao W, Sheng N, Zhu R, Wei F, Cai Z, Zhai $M$, et al. Preparation of dummy template imprinted polymers at surface of silica microparticles for the selective extraction of trace bisphenol A from water samples. J Hazard Mater. 2010;179(1-3):223-9.

14. Kim Y, Jeon JB, Chang JY. CdSe quantum dotencapsulated molecularly imprinted mesoporous silica particles for fluorescent sensing of bisphenol A. J Mater Chem. 2012;22(45):24075-80.

15. Gugoasa LA, Stefan-van Staden R-I, van Staden JF, Coroș M, Pruneanu S. Electrochemical Determination of Bisphenol $A$ in Saliva by a Novel Three-Dimensional (3D) Printed Gold-Reduced
Graphene Oxide (rGO) Composite Paste Electrode. Anal Lett. 2019;52(16):2583-606.

16. Özcan L, Altuntas $M$, Buyuksagis $A$, Türk $H$, Yurdakal $S$. Electrochemical determination of bisphenol A with pencil graphite electrodes modified with $\mathrm{Co}$ (II), $\mathrm{Ni}$ (II), $\mathrm{Cu}$ (II) and $\mathrm{Fe}$ (II) phthalocyaninetetrasulfonates. Anal Sci. 2016;32(8):881-6.

17. Messaoud NB, Lahcen AA, Dridi C, Amine A. Ultrasound assisted magnetic imprinted polymer combined sensor based on carbon black and gold nanoparticles for selective and sensitive electrochemical detection of bisphenol A. Sens Actuators, B. 2018;276:304-12.

18. Tahtaisleyen S, Gorduk O, Sahin $Y$. Electrochemical Determination of Tartrazine Using a Graphene/Poly (L-Phenylalanine) Modified Pencil Graphite Electrode. Anal Lett. 2020:1-21.

19. Dokur E, Gorduk O, Sahin Y. Differential Pulse Voltammetric Determination of Folic Acid Using a Poly (Cystine) Modified Pencil Graphite Electrode. Anal Lett. 2020;53(13): 1-19.

20. Koyun O, Gorduk S, Arvas M, Sahin Y. Electrochemically treated pencil graphite electrodes prepared in one step for the electrochemical determination of paracetamol. Russ J Electrochem. 2018;54(11):796-808.

21. Koyun O, Gursu H, Gorduk S, Sahin Y. Highly sensitive electrochemical determination of dopamine with an overoxidized polypyrrole nanofiber pencil graphite electrode. Int J Electrochem Sci. 2017;12:6428-44.

22. Koyun O, Gorduk S, Arvas MB, Sahin Y. Direct, one-step synthesis of molybdenum blue using an electrochemical method, and characterization studies. Synth Met. 2017;233:1118.

23. Gorduk O. Differential Pulse Voltammetric Determination of Serotonin Using an Acid-Activated Multiwalled Carbon Nanotube-Over-Oxidized Poly (3, 4-ethylenedioxythiophene) Modified Pencil Graphite Electrode. Anal Lett. 2019;53(7):1034-52.

24. Santos DP, Zanoni MVB, Bergamini MF, Chiorcea-Paquim A-M, Diculescu VC, Brett A-MO. Poly (glutamic acid) nanofibre modified glassy carbon electrode: Characterization by atomic force microscopy, voltammetry and electrochemical impedance. Electrochim Acta. 2008;53(11):39914000.

25. Santos DP, Bergamini MF, Santos VA, Furlan M, Zanoni MVB. Preconcentration of rutin at a poly glutamic acid modified electrode and its determination by square wave voltammetry. Anal Lett. 2007;40(18):3430-42. 
26. Liu X, Luo L, Ding Y, Ye D. Poly-glutamic acid modified carbon nanotube-doped carbon paste electrode for sensitive detection of L-tryptophan. Bioelectrochemistry. 2011;82(1):38-45.

27. Wang $L$, Huang $P$, Bai J, Wang $H$, Zhang $L$, Zhao Y. Direct simultaneous electrochemical determination of hydroquinone and catechol at a poly (glutamic acid) modified glassy carbon electrode. International Journal of Electrochemical Science. 2007;2(1):123-32.

28. Ganesh P, Swamy BK. Simultaneous electroanalysis of norepinephrine, ascorbic acid and uric acid using poly (glutamic acid) modified carbon paste electrode. J Electroanal Chem. 2015;752:1724.

29. Yu A-M, Chen H-Y. Electrocatalytic oxidation and determination of ascorbic acid at poly (glutamic acid) chemically modified electrode. Anal Chim Acta. 1997;344(3):181-5.

30. Santos DP, Bergamini MF, Fogg AG, Zanoni MVB. Application of a glassy carbon electrode modified with poly (glutamic acid) in caffeic acid determination. Microchimica Acta. 2005;151(12):127-34.

31. Zhou X, Zheng X, LV R, Kong D, Li Q Electrodeposition of platinum on poly (glutamic acid) modified glassy carbon electrode for non-enzymatic amperometric glucose detection. Electrochim Acta. 2013;107:164-9.

32. Feminus J, Manikandan R, Narayanan SS, Deepa P. Determination of gallic acid using poly (glutamic acid): graphene modified electrode. J Chem Sci. 2019;131(2):11.

33. Özcan A, İlkbaş S. Preparation of poly (3, 4ethylenedioxythiophene) nanofibers modified pencil graphite electrode and investigation of overoxidation conditions for the selective and sensitive determination of uric acid in body fluids. Anal Chim Acta. 2015;891:312-20.

34. Özcan L, Şahin Y. Determination of paracetamol based on electropolymerizedmolecularly imprinted polypyrrole modified pencil graphite electrode. Sens Actuators, B. 2007;127(2):362-9.

35. Koyun O, Sahin Y. Poly (L-Cysteine) modified pencil graphite electrode for determination of sunset yellow in food and beverage samples by differential pulse voltammetry. Int J Electrochem Sci. 2018;13:159-74.

36. Koyun O, Sahin Y. Voltammetric determination of nitrite with gold nanoparticles/poly (methylene blue)-modified pencil graphite electrode: application in food and water samples. Ionics. 2018;24(10):3187-97.

37. Li Y, Hsu P-C, Chen S-M, Lou B-S, Ali MA, AlHemaid F. Simultaneously Determination of Procaine and Catechol at Functionalized Multi-Walled Carbon Nanotube with Poly-Glutamic Acid Modified Electrode. Journal of Biobased Materials and Bioenergy. 2014;8(2):149-57.

38. Lin $\mathrm{B}$, Li Z, Zhang $\mathrm{H}, \mathrm{Wu}$ J, Luo M. Cloning and Expression of the $\gamma$-Polyglutamic Acid Synthetase Gene pgsBCA in Bacillus subtilis WB600. BioMed Research International. 20166; Article ID 3073949, 7 pages.

39. Li $Y$, Zhai $X$, Liu X, Wang L, Liu H, Wang $H$. Electrochemical determination of bisphenol $A$ at ordered mesoporous carbon modified nano-carbon ionic liquid paste electrode. Talanta. 2016;148:3629.

40. Bard AJ, Faulkner LR, Leddy J, Zoski CG. Electrochemical methods: fundamentals and applications: wiley New York; 1980.

41. Ulubay Karabiberoğlu Ş. Sensitive Voltammetric Determination of Bisphenol A Based on a Glassy Carbon Electrode Modified with Copper Oxide-Zinc Oxide Decorated on Graphene Oxide. Electroanalysis. 2019;31(1):91-102.

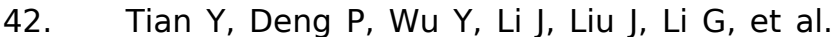
$\mathrm{MnO}_{2}$ Nanowires-Decorated Reduced Graphene Oxide Modified Glassy Carbon Electrode for Sensitive Determination of Bisphenol A. J Electrochem Soc. 2020;167(4):046514.

43. Hu P, Zhu X, Luo X, Hu X, Ji L. Cathodic electrodeposited Cu-BTC MOFs assembled from $\mathrm{Cu}$ (II) and trimesic acid for electrochemical determination of bisphenol A. Microchimica Acta. 2020;187(2):145.

44. Dempsey E, Diamond D, Collier A. Development of a biosensor for endocrine disrupting compounds based on tyrosinase entrapped within a poly(thionine) film. Biosensors and Bioelectronics. 2004;20:367-377.

45. Wang W, Tang J, Zheng S, Ma X, Zhu J, Li F, Wang J. Electrochemical Determination of Bisphenol $A$ at Multi-walled Carbon Nanotubes/Poly (Crystal Violet) Modified Glassy Carbon Electrode. Food Anal. Methods. 2017;10:3815-3824.

46. Mazzotta E, Malitesta C, Margapoti E. Direct electrochemical detection of bisphenol A at PEDOTmodified glassy carbon electrodes. Anal Bioanal Chem. 2013;405:3587-3592.

47. Chen Z, Tang C, Zeng Y, Liu H, Yin Z, Li L. Determination of Bisphenol $A$ Using an Electrochemical Sensor Based on a Molecularly 
Imprinted Polymer-Modified Multiwalled Carbon Nanotube Paste Electrode. Analytical Letters. 2014;47:996-1014.

48. Filik $\mathrm{H}$, Avan AA. Electrochemical Determination of Bisphenol A Based on Poly(Chromotropic Acid) Modified Glassy Carbon Electrode. Current Analytical Chemistry. 2017;13(6):464-473.

49. Lin Y, Liu K, Liu C, Yin L, Kang Q, Li L, Li B Electrochemical sensing of bisphenol $A$ based on polyglutamic acid/amino-functionalised carbon nanotubes nanocomposite. Electrochimica Acta. 2014;133:492-500.

50. Zhuang $Y$, Zhou M, Gu J, Li X. Spectrophotometric and high performance liquid chromatographic methods for sensitive determination of bisphenol A. Spectrochimica Acta Part A: Molecular and Biomolecular Spectroscopy. 2014;122:153-157. 